\title{
Research on Friction Stirs Welding of Aluminum Alloy and Copper Dissimilar Metals
}

\author{
K. Mahender, A. Akhil Reddy, E. Manikanta
}

\begin{abstract}
Unique joining of Aluminum Alloys and Copperaluminum plate thickness $5 \mathrm{~mm}$ resolved through erosion mix welding (FSW) system. The perfect manner parameter that gets to the joint use factual methodologies. Five diverse personnel shape has been used to break up the effect of move-pace shaft speed and nature of microstructures and bending. In the FSW technique, the road to the welding of the base cloth, well under the dissolving temperature, has unfolded new patterns in creating divergent joint talented. Impact on micro welding pace, violent robbery and docile nature of welded joints examined. By changing the parameters of the method, freed from imperfections and excessive effectiveness of the welded joints are created. The share among the dimension device and stick shoulder distance is the maximum dominant issue. From examination of the microstructure is obvious that the set substances to hand pushing a bit of district policies. $\mathrm{HAZ}$ violence in 6061 is seen as
\end{abstract}

At least, in which the welded joints in the doldrums at some stage in the investigation elastic.

\section{INTRODUCTION}

\subsection{Welding}

Las is a method in which two or unique comparative steel may be joined through heating them to unique temperatures with or without using heavy and without using filler metallic. Filler metal has precise dissolution factor across the equivalent of a metal workpiece or barely lower isn't always generally approximately 430degree Celsius.

During the welding edge of the workpiece to be welded warm by way of several distinctive ways. Warmth may be acquired from the electric curve, oxy-acetylene or oxyhydrogen fireplace, hearth metalworker or reaction in phrases of welding thermite compound.

\subsubsection{Autogeneos welding:}

Welding includes strategies wherein a similar metallic which receives together with the help of the filler bar metal.EX same: mellow metallic, forged iron.

\subsubsection{Welding heterogeneous:}

It is a approach in which distinctive metals joined. Metals are joined to the temperature raised base or plastic country and pillar filler used. The soften purpose filler bar isn't as plenty as the figure steel to simple softening.

EX: copper <-> brass.

Characterization welding

Welding grouped into two kinds. They

$\square$ Fusion (or) non welding strain

$\square$ welding Pressure

Revised Manuscript Received on September 14, 2019.

Mr. K. Mahender, Associate Professor, Siddhartha Institute of Technology and Sciences, Narapally, Hyderabad, Telangana, India.

Mr. A. Akhil Reddy, Assistant Professor, Siddhartha Institute of Technology and Sciences, Narapally, Hyderabad, Telangana, India.

Mr. E. Manikanta, Assistant Professor, Siddhartha Institute of Technology and Sciences, Narapally, Hyderabad, Telangana, India.

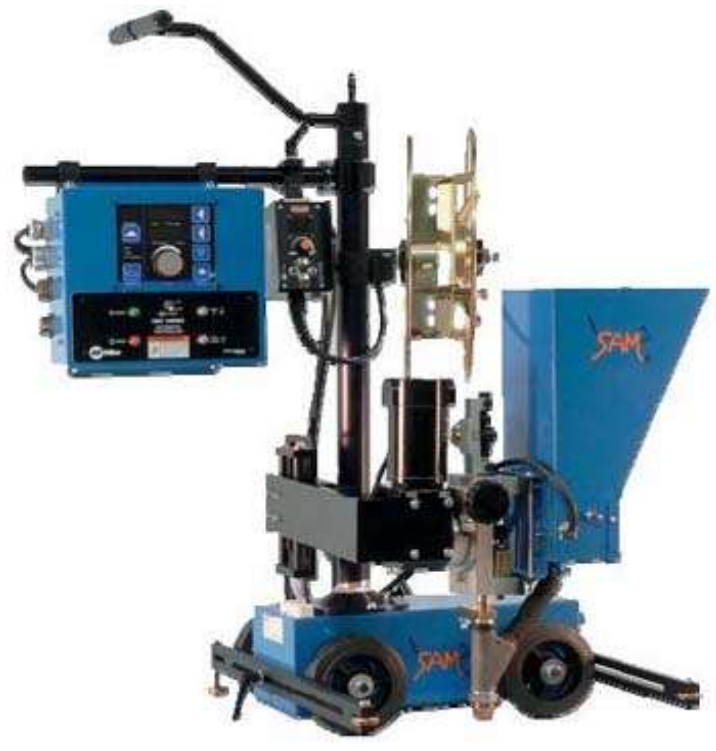

Figure 1:Friction stir welding

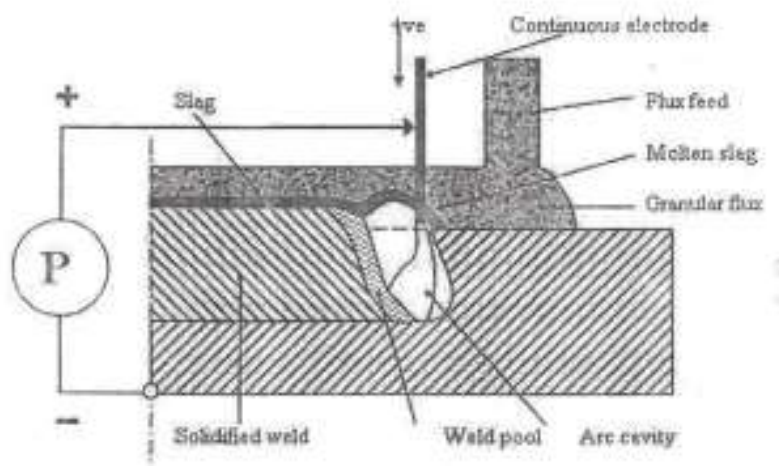

Figure 2: process

Because of the circular segment completely submerged by means of the motion of no radiation disrupt everyday curve to curve the display screen open-welding procedure along these lines essential. Welding motion is not often completely devoured that left an excess amount may be collected either by way of hand or obviously and return to box moves for use again. Despite the reality that the selfloader submerged welding circular segments and profitable existing hardware for a specific utility, the submerged nook Utilize completely automated welding welding tools. One of the simple ideals of the round segments are submerged method is the simplicity with which very well can be integrated into the framework of a fully motorized welding to provide a excessive degree of testimony and predictable weld satisfactory. Weld metallic restoration near one

Published By: 
hundred\% because the terrific misfortune through small scatter. The warmth of the misfortune of the bend which is likewise very low because of the effect of the transition to defend the bed and on this way the warm effectiveness of the procedure may be as high as $60 \%$ evaluation and $25 \%$ for MMA welding.

\section{WRITE SURVEY}

Before the exam by means of Robinson et al (1962) showed that the combination of aluminum in 2219 was through an extended shot the maximum weldable amongst all the warm temperature of excessive satisfactory composite handled. They have idea of a exclusive mixture of heat weldabilities treated aluminum has a place inside the 2000, 6000 and 5000 settings. It additionally indicates that in the 2219 composite does not tend to abuse and most diffused hardening for types inside the welding parameters and methods types. Increased resilient nature together is obtained by making use of electron pillar welding to enroll in the amalgam 2219 (Trazil and Hood, 1969). Utilization of low travel pace, low voltage and excessive amperage welding axis electron is discovered to carry a better joints. It also appeared to them that the width of the weld has a massive impact on EB weld docile nature. Limited dab width bring great progress effects from $193 \mathrm{MPa}$ to 259 $\mathrm{MPa}$ inside the welding completed on the plate $12.7 \mathrm{~mm}$ 2219-T87 cloth. Other tests that led to the immoderate electron welding the shaft measuring $(50-70 \mathrm{~mm}$ thick) 2219-T87 plate through Brennecke (1965) has proven that the effectiveness of the joint can be raised to approximately $80 \%$ by using using electron welding pillars. Despite the reality that the sizeable paintings achieved to improve the welding parameters and to evaluate the mechanical homes of welds Checking no depiction may be accessed at the bar electron welding of 2219 combinations.

Hartman et al 1987 designated that the evacuation of the crown and root fortification plasma extremity variable circular section (VPPA) welds boom the stiffness of the joints. In a equal work they've revealed a low elastic fine to weld VPPA, each unmarried bypass and multi bypass welds unique excellent of the joint project about one hundred forty $\mathrm{MPa}$ in the as-welded situation. A moderate improvement of approximately $10 \mathrm{MPa}$ inside the best of the observe subsequent to the machine off the crown and roots guide, where they have got located a rich neighborhood copper push easy start crack

\section{Technique}

There are two steps within the erosion of units to be considered las mixture; how speedy and the way quick apparatus alternately wading via the interface. Both parameters have a extensive that means and ought to be all in favour of care to ensure a fruitful and advanced welding cycle. The courting among the welding speed and contributions warm temperature in the course of welding is thoughts boggling again, by and massive, generally tend to mention that increasing the turnover price or lessen the rate of site visitors will convey more welding smoke. So, to create an effective weld it is fundamental that the cloth masking the device is hot enough to empower giant plastic flow and restrict the powers important to observe up the device..

\section{TOOL TILT AND PLUNGE DEPTH}

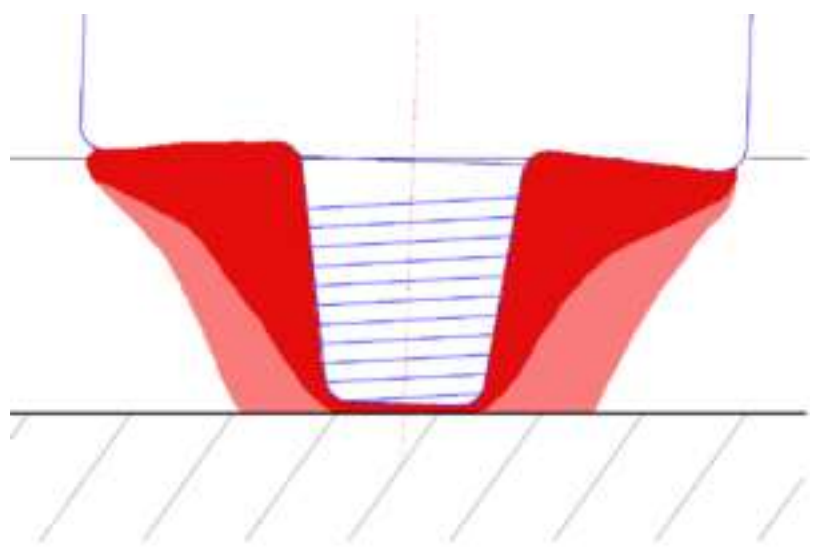

Figure 3:Tool tilt and plunger depth

A picture suggests the dive depth and inclination of the equipment. The device moves to at least one aspect.

The diving intensity is characterised as the absolute intensity of the lowest of the bottom of the outer shoulder of the plate welded and has been visible as the basic parameters to ensure the best of welding. Diving beneath the floor of the plate extending shoulder weight beneath the instrument and make sure that enough fabric Creation in the back of the equipment. Tilting the tool 2-four stages, with the closing purpose being the decrease rear of the the front apparatus, has been discovered to help the advent of this process. Diving depth have to be accurately set to be, each to make certain critical weight loss and to make sure that the device is really infiltrates the weld. Given the excessive burden essential to direct the welding system so that the decrease diving intensity in comparison with the real settings, that can bring a stain at the weld. Then once more diving depth can deliver exorbitant scouring stick with the floor of support plate or vital undermatch weld thickness contrast with the bottom material. Welder load variable has been created to clearly make up for adjustments in the revocation of the tool while the TWI has confirmed curler frame that continues to rise over the plate welding positioning device.
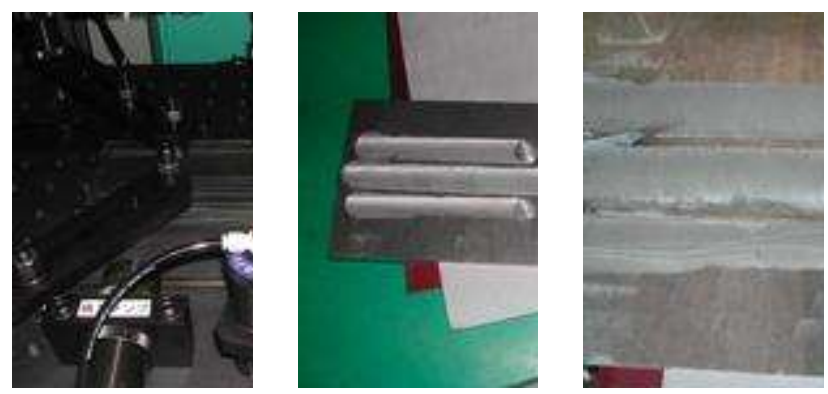

Figure 4:Fixtures and weld 


\section{RESULTS AND DISCUSSION}

\subsection{FRICTION STIR WELDING OF AA6061-Cu}

Erosion mix welding preliminaries have been finished utilizing rubbing mix welding parameters that vary acquired from the writing. The accompanying parameters of the procedure (revolution speed - $800 \mathrm{rpm}$, Welding speed - 40 $\mathrm{mm} / \mathrm{min}$, shoulder distance across to stick measurement three) utilized for contact mix welding to get a decent evaluation welds free illness. Experimentation technique has been utilized to get the framework parameters

\subsection{1 microstructure}

The essential fixings utilized in grain that checks contained reaches out to the moving bearing and countless eutectic and intermetallic particles. Thermo-Mechanically Affected Zone in second as far as affirmed inability particularly grains, the locale Stir surely observed/ThermoMechanically Affected Zone and Thermo mechanical/Heat Affected Zone boundaries. In the Heat Affected Zone (HAZ), in the second part of the weld piece, no generous changes in the grain structure as contrasted and their unaffected fundamental substance.

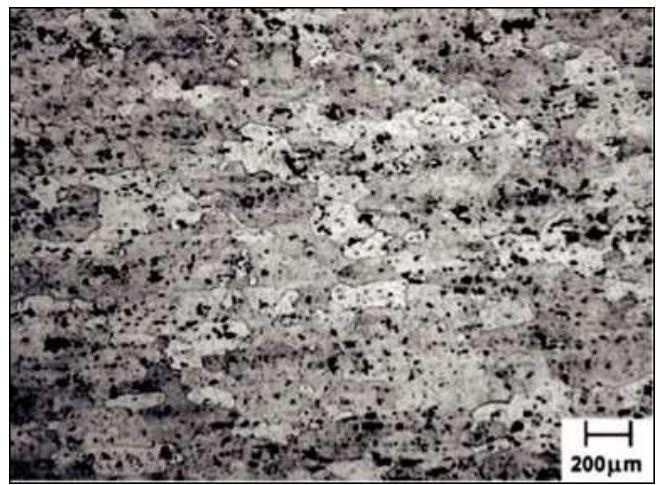

Figure 5:Microstructures of base materials AA6061

Comparison plot for Friction welded plates

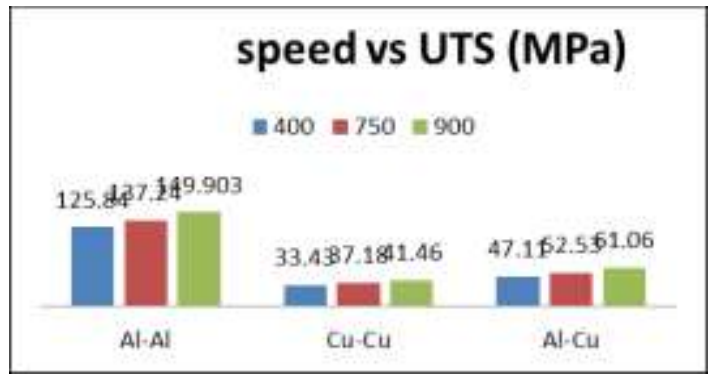

Figure 6: weldedwork pieces

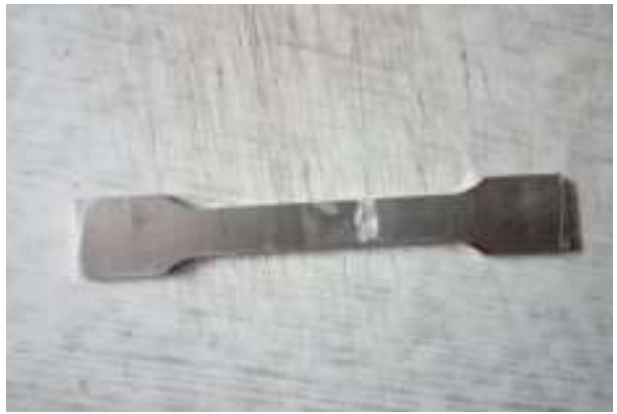

Figure 7: Friction stir welded part Al-Al

\section{CONCLUSION}

From the analyses and the research directed at the rubbing combo welding of unique aluminum composite 6061 to $\mathrm{Cu}$, the accompanying ends are drawn.

Touch mixture welding can create deformity loose butt welds, among AA6061-Cu plates, with a joint productiveness of round $905 \%$ (in view of the yield first rate of the gentler fabric for instance AA6061).

The weld joints had been greater grounded than the gentler base material, and the pliable disappointments seem in the warmth prompted region of the composite 6061.The contact combo welding gadget parameters were better, as for pressure of the Joint and the great degree of settings have been observed. The proper ranges of the rotational velocity, transverse tempo, and the percentage of shoulder distance across to paste breadth (D/d) are $900 \mathrm{rpm}, 15 \mathrm{~mm} / \mathrm{min}$ and a couple of.Five separately.

The present exam suggests that sound butt welded joints amongst AA6061 and $\mathrm{Cu}$ substances can be made using rubbing mix welding, with a joint talent of ninety $5 \%$ (in view of the yield exceptional of the milder fabric as an instance AA6061). It's miles to be noticed that aggregate welding of these distinct aluminum compounds is not potential because of extreme cementing splitting.

\section{REFERENCES}

1. Amancio-Filho, S.T., Sheikhi, S., Dos Santos, J.F., Bolfarini, C. "fundamental exam at the microstructure and mechanical residences of disparate contact mixture welds in flying system aluminum mixtures 2024-T351 and 6056-T4", journal of materials handling innovation, Vol. 206, pp. 132-142, 2008.

2. ASTM E8/E8M - 09. "widespread take a look at strategies for pressure finding out of metal materials1", ASTM global, three July 2010.

3. Atallah, M.M. What is greater, Hanadi G Salem."Friction combination welding parameters: an device for controlling extraordinary grain development all through resulting warmth remedy", materials technological knowhow Engineering, Vol. 391, pp.51-fifty nine, 2004.

4. Baeslack III, W.A., Jata, okay.V., Lienert, T.J. "shape, homes and crack of grinding combo welds in a hightemperature Al-eight.5Fe-1.3V-1.7Si compound (AA8009)", J Mater sci., Vol. Forty one, pp. 2939-2951, 2006.

5. BalaSrinivasan, P., Dietzel, W., Zettler, R., dos Santos, J.F., Sivan, V. "stress erosion splitting weak spot of grinding mixture welded AA7075-AA6056 particular joint", materials technology and Engineering A, Vol. 392, pp. 292-three hundred, 2005.

6. Aluminum Alloy 6013", Metallurgical and substances exchanges B, Vol. 33B, pp. 489-498, 2002.

7. Bob Irving. "Scandium places Aluminum Welding on a brand new Plateau", Welding magazine, 76, 1997, pp. Fifty 3-fifty seven.

8. Brenneccke, M.W. "Electron pillar welded enormous gage aluminum amalgam 2219", Welding magazine, January, pp. 28-40s, 1965

9. Bruni, C., Forcellese, A., Gabrielli, F. What's more Simoncini M. "effect of the/v percentage and sheet thickness on mechanical houses of magnesium aggregate 
FSWed joints", Int J Mater form, Suppl 1, Vol. 3. Pp.1007-1010, 2010.

10. Cavaliere, P., De Santis, A., Panella, F., Squillace, A. "impact of welding parameters on mechanical and microstructural homes of divergent AA6082-AA2024 joints added via erosion combination welding"substances and layout, Vol. 30, pp. 609-616, 2009.

11. Cavaliere, P., Panella, F. "effect of hardware position at the weakness houses of particular 2024-7075 sheets joined via erosion combo welding", journal of substances Processing technology, Vol. 206, pp. 249-255, 2008.

12. Chen, T. Moreover, Lin, W.B. "best FSW procedure parameters for interface and welded quarter sturdiness of disparate aluminum-steel joint", technological knowhow and technology of Welding and becoming a member of, Vol. 15, pp. 279-285, 2010.

13. Chen, Y., Liu, H. Moreover, Jicai, F. "Rubbing mix welding tendencies of numerous warm temperature treated kingdom 2219 aluminum composite plate", materials technological know-how and Engineering A, Vol. 420, pp. 21-25, 2006.

14. Choi, D.H., Lee, C.Y., Ahn, B.W., Yeon, Y.M., Park, S.H.C., Sato, Y.S., Kokawa, H., Jung, S.B. "impact of constant vicinity range in rubbing mix welding of steels with diverse carbon substance", technology and era of Welding and becoming a member of, Vol. 15, pp.299304, 2010

15. Da Silva, A.A.M., Arruti, E., Janeiro, G., Aldanondo, E., Alvarez, P., Echeverria, A., "material move and mechanical behavior of specific AA2024-T3 and AA7075-T6 aluminum composites grating mix welds", materials and layout, Vol. 32, pp. 2021-2027, 2011.

16. Datta, S., Bandyaopadhyay, A. Furthermore, friend, P.Okay. "utilization of Taguchi Philosophy for Parametric Optimization of Bead Geometry and HAZ Width in Submerged Arc Welding the usage of a aggregate of fresh Flux and Fused Flux", international journal of advanced manufacturing generation, Vol. 36, pp. 689-698, 2008.

17. Elangovan, okay. Moreover, Balasubramanian, V. "affects of hardware stick profile and welding velocity at the improvement of touch blend making geared up area in AA2219 aluminum amalgam", journal of materials handling innovation, Vol. Two hundred, pp. 163-one hundred 75, 2008. 